\title{
Explaining positive deviance in public sector reforms in development
}

\author{
Matt Andrews \\ CID Working Paper No. 267 \\ October 2013
}

(C) Copyright 2013 Andrews, Matt and the President and Fellows of Harvard College
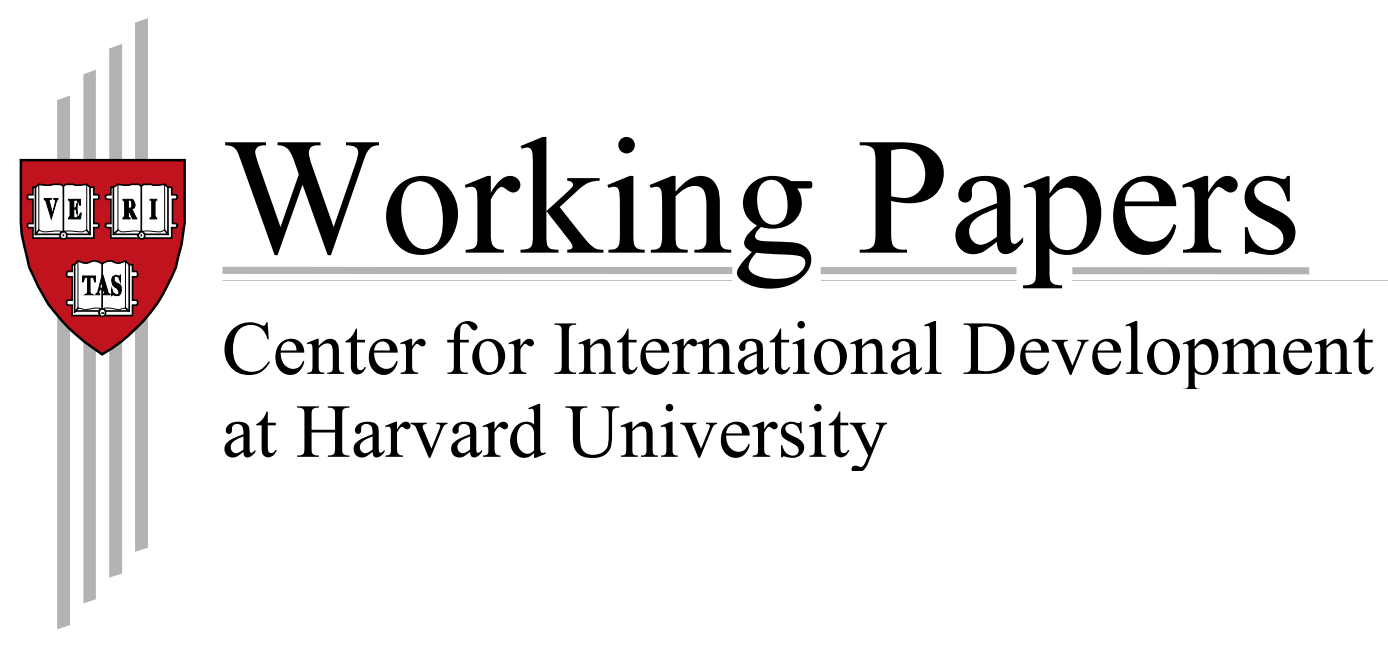


\title{
Explaining positive deviance in public sector reforms in development
}

\author{
Matt Andrews \\ Harvard Kennedy School \\ 416 Rubenstein, 79 JFK Street \\ Cambridge, MA, 02138, USA \\ Matt_andrews@hks.harvard.edu
}

\begin{abstract}
Public sector reforms are commonplace in developing countries. Much of the literature about these reforms reflects on their failures. This paper asks about the successes and investigates which of two competing theories best explain why some reforms exhibit such positive deviance. These theories are called 'solution and leader driven change' (SLDC) and 'problem driven iterative adaptation' (PDIA). They are used to analyze data emerging from a case survey involving thirty cases from Princeton University's Innovations for Successful Society (ISS) program. The bulk of evidence from this study supports a PDIA explanation, but there is reason to believe that SLDC hypotheses also have value. It seems that PDIA and SLDC are two viable paths through which positive deviance can emerge; although PDIA seems to provide the wider path for more positive deviance.
\end{abstract}

Keywords: development, leadership, reform, growth, governance, innovation, case survey JEL classification: $\mathrm{H} 11 ; \mathrm{O} 10 ; \mathrm{O} 19$ 


\section{Introduction}

Public sector reforms are commonplace in developing countries. Much of the literature about these reforms reflects on the failures (or limited successes) of the interventions, and continued weaknesses of governments after reform interventions are complete (Pritchett, Andrews and Woolcock 2013). This paper asks about the successes; instances where reforms have led to more effective solutions to public sector problems than is normal. One might call such successes the 'positive deviants' of public sector reform. Building on the positive deviance approach to understanding and facilitating change, the paper aims to explain the strategies that are associated with these abnormally successful interventions (Pascale, Sternin and Sternin 2010). The goal is not to provide a final test of any one theory of effective reform, but rather to offer a systematic, evidence-based analysis that helps to better construct such theory.

The first part of the paper discusses past experience with reforms and the fact that successes (instances where reforms lead to more functional governments that solve problems) are the exception, not the norm. It refers to such exceptions as 'positive deviants' and explains the underlying rationale behind the positive deviance approach. This gist of this approach holds that understanding the strategies leading to positive deviance can help inform more general success. Building on past work (Andrews, Pritchett and Woolcock 2013; Bond and Hulme 1999), the discussion then proposes competing theories to explain why some reforms are positive deviants. These theories are called 'solution and leader driven change' (SLDC) and 'problem driven iterative adaptation' (PDIA) (Andrews 2013a, 2013b):

- SLDC proposes that abnormal success results when reforms are introduced through a disciplined, formal project process: solutions are fully identified up-front and are the focus of change; the reform is fully planned out at the start and implemented as planned; a champion drives the process; and a pure-form best practice solution is produced.

- PDIA suggests that abnormal success results when reforms are introduced through an iterative process more reflective of 'muddling through': change is motivated by a problem, not a solution; the reform content emerges through a process of experimentation and trial and error; with multiple agents playing different leadership roles; producing a mixed-form hybrid that is fitted to the peculiar context. 
The second section reports on an empirical study intended to shed light on which theory (or parts of the two theories) best explains positive deviance in public sector reforms in development. The study employs a case survey method to synthesize evidence in thirty case studies published by Princeton University's Innovations in Successful Societies (ISS) program. The research method and case sample are introduced and the survey results are discussed. The discussion shows that the bulk of evidence supports a PDIA explanation, but there is reason to believe that SLDC hypotheses also have value. It seems that PDIA and SLDC are two viable paths through which positive deviance can emerge, but PDIA is a far wider path that accommodates and fosters positive deviance more readily. The conclusion identifies some limits of this study, but also suggests how the approach taken in this paper can be built upon to promote a better understanding and theory of why some reforms succeed when most fail—and even to inform reform strategies in future.

\section{Learning from positive deviance in public sector reform in development}

Public sector reform has emerged as a staple of development. Such reform is typically introduced through projects supported by development agencies. These agencies have seen a steadily increasing portfolio of projects since the 1970s. For example, total lending volumes for such interventions in the World Bank grew from an average annual inflation-adjusted total of \$1.8 billion during the 1990s to $\$ 2.7$ billion in the 2000s (World Bank 2012, 2). Growth in the number of World Bank projects with public sector reform content has been significant (going from 469 in the 1980s to 3,235 in the 2000s (Andrews 2013a; Moloney 2009)). Similar patterns show that these reforms dominate project portfolios in other development organizations as well. Public sector reforms are embedded in over half of the operations carried out by Britain's Department for International Development between 2004 and 2010. ${ }^{1}$ They are also evident in

\footnotetext{
${ }^{1}$ Spending on governance accounted for about twenty percent of the Department for International Development's (DFID) activities, whilst more than twenty percent of the spending focused on economic reforms that tended to involve interventions at the interface of the public and private sectors. Beyond this, DFID documents note that institutional reforms are common in sectoral engagements (like water supply and sanitation, health and education). Department for International Development (2011).
} 
over half of the Asian and African Development Banks' project portfolios in the late 2000s, ${ }^{2}$ having comprised less than ten percent of interventions prior to the $1990 \mathrm{~s}^{3}$

The pervasive nature of these reforms is further evidenced in the variety of affected countries. World Bank projects supporting these reforms can be identified in over 140 countries (Andrews 2013a). Similar coverage is provided by agencies like the United States Agency for International Development (USAID) and other bilateral entities, the International Monetary Fund (IMF), and regional development banks. Countries promote reform agendas apart from these external influences too, which further clutters the public sector change discourse.

\section{A 'norm' of failure (or limited success)}

Mounting evidence shows that these reforms commonly produce poor results - either failing to achieve objectives at all or generating changes in forms (like laws and systems) but not having a positive impact on practice or leading to the resolution of governance problems. Using measures from the World Bank Country Policy and Institutional Assessment (CPIA) indicators, for instance, a 2008 World Bank evaluation showed that many countries failed to improve aspects of government quality even after reform projects were completed. The proportion of countries seeing post reform declines or stagnation on these measures ranged from 40 to 60 percent: for example, 58 percent of the countries went backwards on indicators of 'quality of public administration' (World Bank 2008, 38, 46).

The best performing area in the 2008 evaluation was public financial management, where about 60 percent of countries improved their scores. Unfortunately, very few of these improving countries achieved levels on the indicators that suggest they are actually establishing functional systems (Andrews 2011; Andrews 2013a; de Renzio, Andrews and Mills 2010). ${ }^{4}$ This means that many of the countries have produced better laws and processes through reforms, but they still commonly struggle with implementing and using the new laws and processes. As a result, problems fester: money still flows slowly after reforms in most countries, actual spending does not reflect plans or budgets, leakage is high, and resources fail to produce results.

\footnotetext{
${ }^{2}$ Asian Development Bank (2009; 2011); African Development Bank (2012).

${ }^{3}$ Governance operations in the African Development Bank between 1967 and 2006 accounted for 15 percent of all loans. Most took place after the mid-1990s (African Development Bank 2012).

${ }^{4}$ The CPIA guidelines note that a score of 4.5 reflects functionality in the system. Scores below this level indicate that countries are establishing processes and systems but that these are still not fully functional. Fewer than 20 percent of countries break through this score barrier, however, even after decades of reform (Andrews 2013a).
} 
The data used to make these assessments are always open to challenge, but a variety of other studies show similar things. For instance, a 2011 study found even more disappointment (World Bank 2011, 68-76). Fewer than forty percent of the eighty countries receiving World Bank support for public sector reform between 2007 and 2009 registered improved CPIA governance scores in that period. A quarter of these countries actually saw such scores decline, while more than a third stayed the same. The quality of public administration was higher after reforms in only thirteen percent of reforming countries, dropping in about the same sized group. Andrews (2013a) shows that the same observations can be made using multiple data sources, and that these observations resonate with stories emerging from case study analysis (and case survey work). These case-based studies indicate that there are mixed and disappointing results in a range of other institutional reform areas, including privatization (Boubakri, Cosset, and Guedhami 2009), deregulation (Busenitz, Gomez, and Spencer 2000), public financial management (Andrews 2010; de Renzio, Andrews, and Mills 2010), health system modernization (World Bank 2009), and financial liberalization (Karikari 2010; Obstfeld 2009). The studies illustrate, for instance, that many countries do not have more efficient service delivery or better trade volumes or more stable financial sectors after they privatize industries, introduce new trade regulations and liberalize financial systems. The emerging story across such studies is loud and clear and is even accepted by donor organizations (World Bank 2012): in most cases public sector reforms do not lead to more functional governments.

\section{The existence of positive deviants}

However, research also points to the existence of more successful reform experiences that do lead to more functional governments. In these instances, reforms facilitate the establishment of governments that solve problems and achieve the kind of functionality needed to produce public value; new public financial management systems actually foster better resource use, administrative reforms foster better service delivery, trade reforms generate higher volumes of trade, and so forth. These experiences could be called positive outliers; given that they produce results that are better than the norm. 'Positive deviance' is another term that describes such experiences. The term has been used in various literatures but entered the development domain because of the work of Pascale, Sternin, and Sternin (2010). 
These authors argue that positive deviance is observable in every community or field, where some agents find better solutions to problems than their peers even though they have similar resources as their peers and face similar challenges and obstacles. Given such belief, the positive deviance approach has emerged as a way of identifying workable solutions to development's toughest problems. It emphasizes the importance of learning from the positive deviants within the contexts where failure is more normal; and focuses especially on learning about the strategies adopted to find and fit effective solutions.

The importance of this kind of learning cannot be overstated in the international development domain. This importance is reflected in a number of studies that have tried to promote such learning in the past decades. Many of these studies try to explain 'pockets of productivity' or 'islands of excellence' in government organizations in developing countries (Leonard 2010). These include studies like Grindle and Thomas (1991), Leonard (1991), Schneider (1991), Grindle (1997), Tendler (1997), Uphoff, Esman and Krishna (1998), Heredia and Schneider (2002), Grindle (2004), Joshi and Moore (2004), Owosu (2006), Bebbington and McCourt (2007), and Roll (forthcoming). These studies actually investigate different manifestations of what is being called positive deviance in this paper (Leonard 2010). Some focus on oddly successful organizations, others on successful policy interventions, and yet others on successful reforms themselves. In most cases the successes one sees emerged from some or other change process, however, so it is appropriate in all cases to ask how such change (or reform) came about and was consolidated to foster more effective government (where Leonard sees success as the improvement in state capability to sustainably generate public goods).

Recent publications have built on this vibrant (but relatively small) set of studies. For instance, Andrews (2013a) uses a blend of case study and survey methods to identify the strategies common to more successful institutional reforms in a variety of arenas. Similarly, the recent World Bank evaluation of public sector reform (World Bank 2008) looks at project successes across public sector reform types and countries to glean lessons about 'what works and why'. In the same vein, Rodrik (2003) develops narratives of the few (but impressive) high growth experiences in the past fifty years. The 2008 Spence Growth Commission also tried to identify commonalities in the strategies that led to high growth in countries like South Korea, Singapore and Turkey (Brady and Spence 2010). All of these studies implicitly support the view 
that positive deviants exist in the field of development (and reform) and that studying such deviants can foster a better understanding of development and change.

\section{Explaining positive deviance: Competing theories of 'successful' public sector reform}

This is not to say that the studies have converged on simple explanations or even on the same explanations for positive deviance in reforms. In fact, there are many different perspectives on why some public sector reforms seem to be more successful than others (and why some public organizations produce more public value after reforms than others). To illustrate this, Leonard (2010) summarizes the literature on 'pockets of productivity' to show what he calls "five implicit meta-hypotheses." These relate to context, organizational leadership and structure, process, and the nature of the task being undertaken. Leonard breaks the meta-hypotheses down into over 50 stand-alone hypotheses that reflect how hard it is to tell any uncomplicated and coherent story.

In the interests of providing just such a story, however, the current paper pulls together a selection of hypotheses about the process of reform to generate competing theories of 'successful' public sector reform. The hypotheses emerge particularly from the recent World Bank and Growth Commission reports (World Bank 2008; Brady and Spence 2010) and the work of Andrews and others (Andrews, Pritchett and Woolcock 2013; Andrews 2013a; Pritchett, Woolcock and Andrews 2013) and earlier studies on the topic of 'process' theory (Bond and Hulme 1999). The hypotheses are responses to basic questions: What motivates reform? How do reforms get implemented? Who leads the process? What do the 'new' government and governance structures look like? A first theory combining such answers is called solution and leader driven change (SLDC) and a second is called problem driven iterative adaptation (PDIA). In many ways these approaches are like the 'blueprint' and 'process' approaches proposed by earlier work (Bond and Hulme 1999).

SLDC proposes that abnormal success results from reforms that are introduced through a disciplined, formal project process: solutions are fully identified up-front and are the focus of change; the reform is fully planned out at the start and implemented as planned; a champion drives the process; and a pure-form best practice solution is produced.

- The emphasis on clearly identified solutions as a motivation for change reflects the Growth Commission view that successful reform requires an initial decision to choose the 
"correct model" (Brady and Spence 2010, 6). 'Solutions' are provided across the development spectrum (often in indicator sets ${ }^{5}$ ) and are argued to guide and motivate reforms (inspiring change because there is a 'solution' to adopt and a promise of gains). Such thinking yields a simple hypothesis and expectation of what one would observe at the start of a reform process: H1. Successful reform is motivated by the promise of a solution. One expects reform solutions to be fully identified at the more successful reform's start and that reforms will be motivated by such solution, and focused on implementing the solution.

- The focus on pre-planning and implementing reforms as planned reflects the idea that thorough project specification fosters project success. This idea is implicit in the way organizations like the World Bank stress project preparation and highly detailed ex ante programming. The 2008 World Bank public sector reform evaluation states that this kind of pre-planning only works if the project is actually implemented according to plan, however, and suggests that more successful reforms have this characteristic (World Bank 2008). This view is echoed in the Growth Commission's observations that growthenhancing reform requires having clear objectives and an authorizing environment in which such objectives can be systematically implemented. ${ }^{6}$ These observations and views yield the following hypothesis: H2. Successful reforms will be implemented according to a specified plan of action. One would expect to find that the reform content of these successful reforms is fully planned out at the start of the change process, and that the reforms are implemented as planned.

- It is commonly held that this kind of reform is successful when driven by high-level individuals in positions of authority and influence. The perspective is reflected in the general emphasis on reform 'champions' in organizations like the World Bank (World Bank 2008). It is also explicit in the Growth Commission's work, which notes that such leaders are central in most of the instances where governments have fostered high levels of growth over sustained periods. According to the commission, such individuals facilitate these achievements when they make decisions that introduce the right policies

\footnotetext{
${ }^{5}$ These inform countries about the 'right' policies needed to foster business activity, or manage public finances, or tackle corruption, and beyond.

${ }^{6}$ Brady and Spence (2010) note, for instance, that plans were vital in driving development processes in Singapore and South Korea. These plans are argued to have provided both a direction for reform and acted as a disciplining factor in the implementation process. Leaders could assess progress according to plan, for instance, and accountability for action was clear.
} 
and then ensure that the policies get implemented. ${ }^{7}$ The hypothesis emerging from such thought is simple: H3. Successful reform is led by a champion; some high-level individual with authority. As a result, one would expect to find a single individual in a high-level position identified consistently as the 'leader' of the more successful reform.

- Given a belief in 'correct' models in many parts of development (as echoed in Brady and Spence (2010)) one hypothesis is that that positive deviants are reformers that actually manage to adopt the best practice solutions they focus on replicating. This line of argument is implicit in the way development organizations routinely evaluate reform progress as compliance with 'good' or 'best' practice scripts. The implied argument is that adopting such scripts will lead to functionality and success, which frames a basic hypothesis: H4. Successful reforms produce the 'right' best practice solutions commonly argued as necessary to foster good governance. One expects to find that final successful reform products will resemble pure-form best practice solutions identified at the start of reform.

These four arguments are combined in the first column of Table 1, which suggests what a solution and leader driven change (SLDC) theory looks like. It is a simplified theory that may even be criticized as a straw man representation of the implicit logic behind structured project interventions. This is arguably not an accurate perspective, however, as others refer to similar constructs. Bond and Hulme (1999, 1340), for instance, speak of the 'blueprint' approach which is described as follows: "Prescribed steps lead through the stages of the project cycle; experts design and control activities; detailed planning at the beginning specifies objectives, targets, outputs, resources, and schedules; local institutions are bypassed if they have inadequate capacity and the job of management is to implement as closely as possible to plan."

The four SLDC hypotheses are thus argued to represent established and entrenched views on what makes for effective reform in development (and reflect actual behaviors in the development community-especially where such is dominated by reductionist economists, engineers or infrastructure experts who believe in the value of rational and disciplined process and the idea that there are 'answers' to development's problems). These four hypotheses are contrasted with ideas proposed to combine into an alternative theory explaining positive deviance in reform - problem driven iterative adaptation (PDIA).

\footnotetext{
${ }^{7}$ Brady and Spence $(2010,7)$.
} 
Table 1. Eight hypotheses, and two theories, to explain positive deviance in public sector reforms

\begin{tabular}{|c|c|c|}
\hline Key Question & $\begin{array}{l}\text { Solution and leader driven change } \\
\text { (SLDC) }\end{array}$ & Problem driven iterative adaptation (PDIA) \\
\hline $\begin{array}{l}\text { A. What } \\
\text { motivates } \\
\text { reform? }\end{array}$ & $\begin{array}{l}\text { H1. Successful reform is motivated by } \\
\text { the promise of a solution. } \\
\text { One expects reform solutions to be } \\
\text { fully identified at the reform's start } \\
\text { and that reforms will focus on } \\
\text { implementing solutions. }\end{array}$ & $\begin{array}{c}\text { H5. Successful reform is motivated by a } \\
\text { problem (performance deficiency). } \\
\text { One expects that a problem will be clearly } \\
\text { identified at the start of reform, promoting } \\
\text { an appetite for change and a process of } \\
\text { change. }\end{array}$ \\
\hline $\begin{array}{l}\text { B. How do } \\
\text { reforms get } \\
\text { implemented? }\end{array}$ & $\begin{array}{l}\mathrm{H} 2 . \text { Successful reform is implemented } \\
\text { according to a specified plan of action. } \\
\text { One expects to find that reform } \\
\text { content is fully planned out at the start } \\
\text { of the change process, and is } \\
\text { implemented as planned. }\end{array}$ & $\begin{array}{l}\text { H6. Successful reform emerges through a } \\
\text { process of experimentation as agents find } \\
\text { and fit content to context. } \\
\text { One expects to find reform content emerging } \\
\text { through a process of experimentation and } \\
\text { trial and error. }\end{array}$ \\
\hline $\begin{array}{l}\text { C. Who leads } \\
\text { the reform } \\
\text { process? }\end{array}$ & $\begin{array}{l}\text { H3. Successful reform is led by a } \\
\text { champion; some high-level individual } \\
\text { with authority. } \\
\text { One expects to find a single individual } \\
\text { in a high-level position identified } \\
\text { consistently as 'leader' of the reform. }\end{array}$ & $\begin{array}{l}\text { H7. Successful reform is led by a group of } \\
\text { agents who provide various functions } \\
\text { required to make reform work. } \\
\text { One expects to find multiple individuals } \\
\text { identified as playing key functional roles in } \\
\text { the reform process. }\end{array}$ \\
\hline $\begin{array}{l}\text { D. What do the } \\
\text { 'new' } \\
\text { government/ } \\
\text { governance } \\
\text { structures look } \\
\text { like? }\end{array}$ & $\begin{array}{l}\text { H4. Successful reforms produce the } \\
\text { 'right' best practice solutions } \\
\text { commonly argued as necessary to } \\
\text { foster good governance. } \\
\text { One expects final reform products to } \\
\text { resemble pure-form best practice } \\
\text { solutions identified at reform's start. }\end{array}$ & $\begin{array}{c}\text { H8. Successful reforms produce hybrid } \\
\text { solutions that blend ideas from inside and } \\
\text { outside the context; all fitted to the context. } \\
\text { One expects to find that final reform } \\
\text { products are mixed-form products of many } \\
\text { influences; including best practices and } \\
\text { internal ideas. }\end{array}$ \\
\hline
\end{tabular}

PDIA suggests that abnormal success results when reforms are introduced through an iterative process more reflective of 'muddling through' (Lindblom 1959). As a theory, it relates to many other studies and arguments (as discussed in Andrews, Pritchett and Woolcock, 2013) and the participatory work of Chambers (1997), Korten (1980) and Uphoff (1990) as well as the managerial work of authors like Rondinelli (1993). Given such roots, PDIA proposes that successful change is usually motivated by a problem, not a solution; the reform content emerges through a process of experimentation and trial and error; with multiple agents playing different leadership roles; producing a mixed-form hybrid that is fitted to the peculiar context.

- The first argument is that institutional reforms are more successful when motivated by problems that local people care about. The idea is that problems create an urgency needed to foster change, an awareness of potential loss that outweighs the expected loss associated with change and reform (Cameron 1986; Seo and Creed 2002; Vis and van Kersbergen 2007). A problem focus also points to the weaknesses of extant structures, 
guiding reformers in how to de-institutionalize such (Greenwood, Suddaby and Hinings 2002). A problem focus further motivates a search for viable alternatives to replace faulty incumbents; contextualizing the search to ensure that 'solutions' fit contextual realities. Such thinking yields a hypothesis and expectation of what one would observe at the start of a more successful reform process: H5. Successful reform is motivated by a problem (or performance deficiency). One expects that a problem will be clearly identified at the start of reform, promoting an appetite for change and a problem driven process of change.

- The approach also emphasizes 'purposive muddling' in the reform process (Andrews 2013a). This proposes that reforms are incremental, emerging via multiple steps through which reformers learn about what works and why, build capacities to introduce new mechanisms, and achieve short-term results to grow support for change (McCay 2002). This 'finding and fitting' involves a localized focus on problems and contextual realities, such that reform choices address matters that are politically relevant and viable given capacities and constraints (Rose 2003). Solutions are expected to emerge through processes of discussion, translation, and experimentation (Dorado 2005; Garud and Karnøe 2003; Ostrom 2008). This perspective yields the hypothesis: H6. Successful reform emerges through a process of experimentation as agents find and fit content to context. One expects to find reform content emerging through a process of experimentation and trial and error.

- A third piece of this perspective is that institutional reform requires the engagement of a broad set of agents (Andrews 2008; Andrews, McConnell and Wescott 2010). Individual champions are not enough, and even small groups of centrally located actors are insufficient. Multiple functions are needed to foster an awareness of the need for change, introduce new ideas to drive reform, motivate and authorize adjustment, and more (Hackman and Walton 1986). These functions typically come from different agents at different positions in reform networks (Greenwood and Suddaby 2006). Given this, reforms are likely to emerge and diffuse successfully only where diverse sets of players are mobilized, including elites, peripheral agents, and distributed implementers. The hypothesis emerging from such thought is simple: H7. Successful reform is led by a group of agents who provide various functions required to make reform work. One expects to find multiple individuals identified as playing key functional roles in the reform process.

- This approach emphasizes finding and fitting solutions to context, and notes that processes succeed when allowing solutions to emerge through a process of brioclage, as 
hybrid blends of different attributes - with some external content and some internal content - rather than pure form replicas of any one idea (Dacin, Goodstein and Scott 2002; Ostrom 2008). Ostrom $(2008,47)$ summarizes such view; "There must be the generation of new alternatives, [and] selection among new and old combinations of attributes that are successful in a particular environment." The argument is that 'new alternative' hybrids will lead to functionality and success, which informs a basic hypothesis: H8. Successful reforms produce hybrid solutions that blend ideas from inside and outside the context and are fitted to the context. One expects to find that final reform products are mixed-form products of many influences; including best practices and internal ideas.

\section{Examining positive deviance: A case survey study}

The four PDIA hypotheses are organized into a single theory in Table 1, alongside the column showing the SLDC hypotheses. As presented, SLDC and PDIA are intended to provide competing explanations for how public sector reforms in development achieve success. In respect of this paper, the question is whether one of the two theories best explains the emergence of positive deviants - cases of abnormal success. It is difficult to test this, however, partly because the bulk of empirical evidence about public sector reforms in development—both failures and success - comes in the form of case studies. These studies provide detailed renditions of experiences in particular reform engagements. They do not allow easy generalized testing of theories, however, or even garnering of lessons across cases. The case survey method has emerged to fill such gap. It was devised as a means of generalizing from case studies using a closed-ended questionnaire (Lucas 1974; Yin and Heald 1975) to facilitate the analysis of "original qualitative case studies in a rigorous, highly structured ... way" (Newig and Fritsch $2009,5)$. The current section discusses an application of this method designed to foster a better understanding of positive deviance in public sector reform in development.

\section{Research method and sample}

The case survey method is a form of meta-analysis. It requires one to select a sample of relevant cases, develop a coding scheme to convert qualitative descriptions into quantified variables, code each case (using multiple coders), and then analyze the coded data (Bullock and Tubbs, 1987; 
Larsson, 1993; Larsson and Lubatkin, 2001). It has been used across the social sciences, including in the literature on public sector reform. Probably the most prominent application in this literature was by Wolf (1993), who conducted a case survey of bureaucratic effectiveness in US cabinet agencies. The study used coded data to test competing theories of effectiveness across various agencies, which is a similar approach to that taken in this paper.

The sample used in the current paper emerged from a purposive sampling process focused on selecting cases of public sector reform in developing nations that: (i) are considered abnormally successful (because they fostered functional improvements in the way governments work), (ii) have enough information to allow analysis, and (iii) cover a variety of public sector reform types. In this respect, thirty studies were selected from Princeton University’s repository of Innovations for Successful Societies (ISS) cases. These cases were chosen by ISS staff because they come from countries "once considered fragile states" and have generated "sustained improvement in institutional performance and economic growth." ${ }^{8}$ Given such selection process, the ISS reforms were expected to be abnormally successful (given their contexts) in fostering functional improvements in public organizations. Forty cases were identified initially, after discussions with ISS staff (intended to ensure that all cases meant the criteria listed above). Two graduate students were then asked to rate each case and check whether they met the criteria (with questions asked about the degree and nature of "success" ${ }^{9}$ and the information density in the cases). In this process, the students were tasked with ensuring that the cases did not inflate success but rather provided real stories with specific evidence of functional improvements in the governments involved (given potential bias towards inflating the 'success' in each story). ${ }^{10}$

The sample size was decreased to 30 cases after this process. The selected cases were ones in which both raters agreed that the story exhibited important 'success' (functional improvement was evident) and was told in sufficient detail to allow analysis. The final list is

\footnotetext{
${ }^{8} \mathrm{http}: / /$ www.princeton.edu/successfulsocieties/aboutiss/

${ }^{9}$ It is difficult to establish a common and clear perspective on what constitutes 'success' in reforms. Vanlandingham et al (2005) and Roberts and Andrews (2005) show that reforms can appear successful in changing what governments look like, but could also fail to produce results. De Renzio et al. (2010) and Andrews (2013a) advocate looking at whether reforms foster changes that help governments become more functional.

${ }^{10}$ The raters were asked to score each case on 'whether it could be called a success'. They were also asked to answer whether the case held value for academics or practitioners examining successful reform. There was sufficient agreement across raters that all thirty cases used for the final analysis could be called successful.
} 
shown in Annex 1 and included examples of reform in revenue agencies, local governments, national level policymaking, anti-corruption reform, civil service systems, and beyond.

The obvious limit to this sampling approach is that there are no cases of failure or even questionable success (at last given the selection criteria). The lack of 'counterfactual' cases means that the study here cannot be seen as an explicit 'test' of what explains positive deviance. Rather, it is a step in determining a theory to understand such. Another limit relates to the potential sampling bias inherent in drawing all cases from one publication source, where one expects a common method of identifying cases, doing research, and writing the final story. It is difficult to know precisely what kinds of bias to expect. However, it is apparent that the ISS cases are organized into 'focus areas' and this might suggest that they are biased to telling stories about how best practice solutions represented in these areas are introduced (like independent revenue agencies, for instance). ${ }^{11}$ There is also a common charge that published cases like those in the ISS repository tell stories about heroic figures and simplify the narrative to center on such person. ${ }^{12}$ If true, one would expect a bias in favor of the SLDC approach to explaining success (where individual leaders drive the process). One might also expect case writers to adopt a linear story-telling approach that could also bias the narratives towards telling an SLDC type story (where a hero introduces a solution through a top-down process that can be easily reproduced).

To facilitate measurement and analysis in each case, the author constructed a survey questionnaire based (mostly) on the hypotheses formulated above. The major questions were closed ended and used 3 or 5 point scales. ${ }^{13}$ The questionnaire also allowed raters an opportunity to provide open-ended descriptions of the rationale behind their rating decisions. The questionnaire was pretested and then used for coding the full sample, which was done by 12 raters. The raters were all graduate students with a background in public sector reform but with no experience in the particular cases. At least two raters coded all the cases. The inter-rater reliability was calculated using a simple measure of percent agreement and varied from 50 to 90 percent (the low percent agreement questions are used with caveats). Coding discrepancies were resolved by the lead author by computing the arithmetic mean in each case to obtain a single

\footnotetext{
${ }^{11} \mathrm{http} / / / \mathrm{www}$. princeton.edu/successfulsocieties/content/

${ }^{12}$ Barzelay 2007.

${ }^{13}$ Similar to the approach taken in Beierle and Cayford (2002), Newig and Fritsch (2009), Wolf (1993) and Yin and Heald (1975).
} 
coding for each variable and case. Such approach is considered appropriate for this type of research, given that there is actual value in capturing and reflecting the subjective differences in opinion of 'expert' coders (Newig and Fritsch 2009).

The author adopted two approaches to further foster reliability and validity in the final codes. First, the author cross-referenced final codings with the qualitative explanations provided by raters. This allowed the opportunity to ensure that the codes were congruent with the written rationales given by each rater. Second, the author sought expert judgment of third parties who had been involved in a sub-set of the cases (ten in total). These third parties were asked whether final codes made sense given their experience. In all ten cases the third parties agreed with over 90 percent of the measures. Whereas these kinds of checks allow a higher degree of confidence in the data, they do not address all potential issues with reliability and validity of the data, which must be seriously considered given the subjective nature of the coding approach (and, inevitably, of the cases themselves). Basic statistical techniques were used to assess the coded data. These included mid-point calculations, frequency counts, and bivariate correlation. Whereas more rigorous methods are required to test any theory, these simple measures are commonly used and appropriate in case surveys - especially those intent on contributing to new theory development (Mintzberg et al. 1976; Herek et al. 1987; Newig and Fritsch 2009; Yin and Heald 1975).

\section{Evidence and discussion}

Table 2 shows the frequency counts and averages emerging from analyses of all thirty cases. These are organized as they relate to the four questions posed earlier (by row) and the two alternative theories discussed in the prior section (by column). For instance, the first line synthesizes evidence about 'what motivates reform' in these positive deviance cases. Two competing hypotheses were evaluated. The first hypothesis was that successful reforms would be motivated by the presence of a 'solution' (the SLDC hypothesis) and the fifth hypothesis was that these reforms would be motivated by some kind of problem (the PDIA hypothesis). Evidence is more supportive of the latter PDIA hypothesis, with raters giving 19 cases scores over 4 (out of 5) when asked if 'the reform was motivated by some kind of problem in the context.' The average score was 4.2 on this question, and only 3 cases scored below $2.5 .{ }^{14}$ In

\footnotetext{
${ }^{14}$ There was a high level of agreement on answers to this question (93\%). This meant that both raters agreed on the exact coding in $50 \%$ of the cases and the raters only differed by one point in a further $43 \%$ of the cases.
} 
contrast, raters only scored one case as a 5 when asked if the 'reform content was fully known at the start' (something one would expect if the reform was motivated by a solution). Raters gave 20 cases scores below 2.5 when assessing this question, and 7 scored it the minimum score (1) to indicate major disagreement with the statement. ${ }^{15}$ The average score was 2.4 out of 5 . This suggests that a majority of cases considered positive deviants were motivated by problems (not solutions as suggested in the SLDC theory).

Table 2. Case survey evidence explains positive deviance in public sector reform in development

\begin{tabular}{|c|c|c|}
\hline Key Question & $\begin{array}{l}\text { Solution and leader driven change } \\
\text { (SLDC) }\end{array}$ & $\begin{array}{l}\text { Problem driven iterative adaptation } \\
\text { (PDIA) }\end{array}$ \\
\hline $\begin{array}{l}\text { A. What motivates } \\
\text { reform? }\end{array}$ & $\begin{array}{l}\text { H1. "Reform content was fully } \\
\text { known at the start" } \\
6 \text { cases scored } 4 \text { or above. } \\
20 \text { cases scored below } 2.5 \text {. } \\
\text { Average out of } 5: 2.4^{16}\end{array}$ & $\begin{array}{l}\text { H5. "The reform was motivated by some } \\
\text { kind of problem in the context" } \\
19 \text { cases scored } 4 \text { or above. } \\
3 \text { cases scored below } 2.5 \text {. } \\
\text { Average out of } 5: 4.2^{17}\end{array}$ \\
\hline $\begin{array}{l}\text { B. How do } \\
\text { reforms get } \\
\text { implemented? }\end{array}$ & $\begin{array}{l}\text { H2. "The reform content was fully } \\
\text { planned out at the start and was } \\
\text { implemented as planned" } \\
4 \text { scored } 4 \text { or above. } \\
18 \text { scored below } 2.5 \text {. } \\
\text { Average out of } 5: 2.3^{18}\end{array}$ & $\begin{array}{l}\text { H6. "The reform content emerged } \\
\text { through the process, with } \\
\text { experimentation and trial and error" } \\
13 \text { scored } 4 \text { or above. } \\
8 \text { scored below } 2.5 \\
\text { Average out of } 5: 3.4^{19}\end{array}$ \\
\hline $\begin{array}{l}\text { C. Who leads the } \\
\text { reform process? }\end{array}$ & $\begin{array}{c}\text { H3. "Was there a clear leader } \\
\text { involved in the change process?" } \\
12 \text { cases yes and identified the same } \\
\text { person as 'the leader'. }\end{array}$ & $\begin{array}{l}\text { H7. "Was there a clear leader involved in } \\
\text { the change process?" } \\
18 \text { cases said 'no' or raters identified } \\
\text { multiple people as 'the leader'. } \\
\text { Also, in all cases raters identified } \\
\text { multiple agents providing functions } \\
\text { commonly associated with 'leaders'. } \\
\text { Average agents per case: } 19 .^{20}\end{array}$ \\
\hline $\begin{array}{l}\text { D. What do the } \\
\text { 'new' government/ } \\
\text { governance } \\
\text { structures look } \\
\text { like? }\end{array}$ & $\begin{array}{l}\text { H4. "The final reform product } \\
\text { reflects best practice designs from } \\
\text { western or other developing } \\
\text { countries only." } \\
\text { There were only } 2 \text { cases where the } \\
\text { final reform product reflected a 'best } \\
\text { practice'. }\end{array}$ & $\begin{array}{c}\text { H8. "The final reform design } \\
\text { incorporated ideas from a range of } \\
\text { different areas." } \\
\text { There were } 28 \text { cases where the final } \\
\text { reform products were a mix of sources. } \\
\text { The average number of sources seen to } \\
\text { influence reform designs: } 2.35 .^{21}\end{array}$ \\
\hline
\end{tabular}

Source: Author's analysis

The evidence in respect of these first two hypotheses is presented in Figure 1 as well, where one can clearly see the more frequent support for the PDIA hypotheses. The box plot

\footnotetext{
${ }^{15}$ There was a high level of agreement on answers to this question (90\%).

${ }^{16}$ Standard deviation was 1.27 .

${ }^{17}$ The standard deviation was 0.77 .

${ }^{18}$ The standard deviation was 1.16 .

${ }^{19}$ The standard deviation was 0.98 .

${ }^{20}$ The standard deviation was 12.8 .

${ }^{21}$ The standard deviation was 0.56 .
} 
shows that the different sets of coders gave much higher scores when noting that reforms were 'problem driven' than they did when considering if the reforms were 'solution driven' (where solutions were fully known at the start). The interquartile range is higher in respect of the PDIA explanation in this figure, illustrating how many more cases were rated as 'problem driven' instead of solution driiven.

Figure 1. What drives reform?

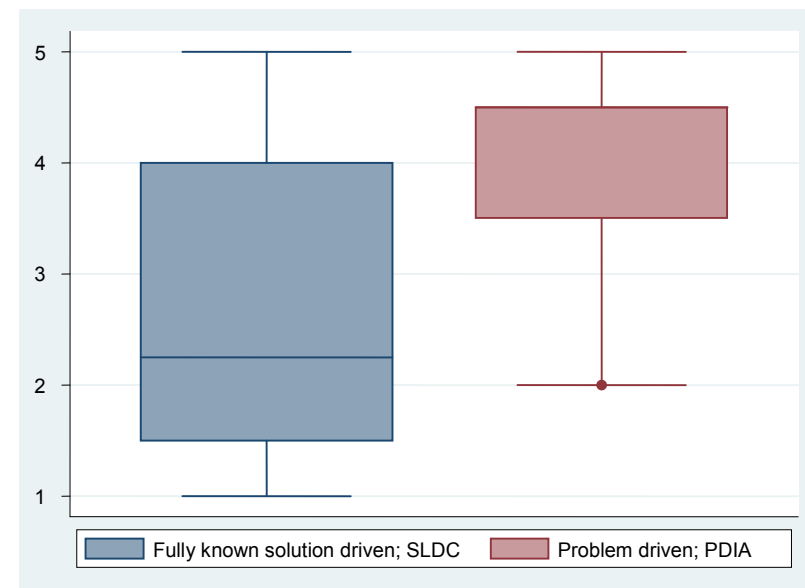

Figure 2. How does implementation happen?

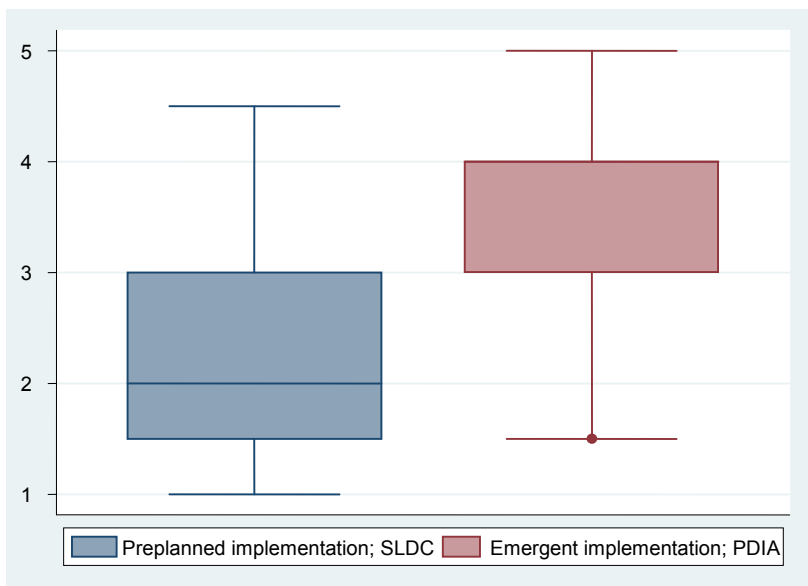

Figure 2 shows the same in respect of the two hypotheses about implementation. Raters gave 13 cases scores of 4 or higher (out of 5) when asked if 'the reform content emerged through the process, with experimentation and trial and error. ${ }^{22}$ A further 9 cases were given scores above 3 (meaning there was evidence of experimentation and emergence). The average score was 3.4, which was a full point higher than the average score registered in response to the question, 'Was the reform content fully planned out at the start of the change process, and implemented as planned?' Raters combined to give 18 countries fewer than 2.5 points when registering answers to this question, suggesting that most of the cases had explicit evidence showing that reforms emerged through the process and were not pre-designed (as the SLDC approach would suggest). ${ }^{23}$ The box plot shows that there is no overlap between the interquartile ranges in each case; scores for preplanned implementation were significantly lower than those for 'emergent' implementation - the PDIA explanation.

\footnotetext{
${ }^{22}$ The level of inter-rater agreement was $77 \% .12$ sets of raters agreed on the exact score; 11 differed by one point.

${ }^{23}$ The level of inter-rater agreement was $70 \%$. 8 sets of raters agreed on the exact score;13 differed by one point.
} 
This PDIA perspective was supported in other areas of the survey, where raters noted that 19 of the cases had high levels of 'learning' that contributed to the final solution (and were thus not predesigned). Raters of a similar number of cases (20) agreed with the statement that 'information collected through monitoring and evaluation mechanisms (formal or informal) was fed back into the change process and allowed adjustments to the reform.'

The evidence in support of question C ('who leads the reform process') is more nuanced. Raters were asked whether there was a 'clear leader involved in the change process' and then they were asked to name this leader. The level of inter-rater agreement on these questions was just $50 \%$, which is surprisingly low given the assumed bias of ISS cases discussed earlier (and the expectation that published cases commonly focus on telling stories about outstanding protagonists). ${ }^{24}$ Only 12 sets of raters agreed that there was a clear leader in the case, and identified the same person as that leader. In 8 cases one rater said there was a leader and one said there was no leader. In 4 cases both raters said there were many leaders, identifying a group of leaders in response to the question. In 3 cases, both raters said there was no single leader. In 2 cases both raters said there was a leader but identified different people as 'the leader'. The raters were also asked to identify who provided functions commonly associated with 'leaders' (Andrews 2013; Hackman and Walton 1986). These included 'substantive', 'procedural', and 'maintenance' contributions. ${ }^{25}$ In all cases, raters identified multiple agents providing these functions, with an average of 19 agents per case. Interestingly, where they were identified, the 'clear leader' was seen to provide (at least primarily) a very narrow set of functional contributions - authorizing change, motivating the change, and convening groups (most commonly teams) to make the change happen. The other leadership functions were played by members of a broader group.

While the evidence about leadership is nuanced, therefore, it seems more supportive of a PDIA explanation than an SLDC explanation for how positive deviance comes about. The same can be said for evidence shown in the last row of Table 2; related to the final product of the

\footnotetext{
${ }^{24} 15$ of the 30 sets of raters agreed that either there was a leader (and named the same leader) or that there was no leader. There was disagreement in the other 14 sets of raters; meaning that one rater identified a 'leader' and the other did not, or the raters identified different agents as the leader.

${ }^{25}$ Substantive contributions include activities like 'identifying problems' and 'identifying solutions'. Procedural contributions include 'providing authority' and 'motivating'. Maintenance contributions include 'convening' and 'connecting' to allow engagement that fosters change.
} 
reform process. The SLDC approach leads one to expect that successful reforms will ultimately resemble a pure-form version of international best practice (considered the 'right' solution and assessed in common indicator sets used by development organizations). A successful public budgeting system will include a multi-year framework akin to that accorded an ' $A$ ' in the multidonor Public Expenditure and Financial Accountability (PEFA) framework, for instance, and have a competitive bidding process in the procurement regime (like that propagated by the United Nations). A successful revenue reform will produce an independent revenue agency with a specific set of checks and balances and accountability mechanisms. In contrast, the PDIA approach would have one expect that final reform products look more like hybrids, combinations of many influences into locally fitted (and often peculiar) forms (that function regardless). A functional budgeting system may cover one year or many years. Similarly, a functional procurement system might incorporate elements of competitive bidding alongside other purchasing modalities. A functional revenue system might not have an independent agency at all.

To assess if evidence spoke more readily to one of these explanations, raters were asked about the influences they saw on final reform products. They could indicate if there was strong evidence that the reform product had been influenced by external western best practice, developing country best practice (emerging from south-south collaborations), past practices within the country, and emerging ideas within the country. In their responses to this set of questions, only two of the sets of raters agreed that the final product was influenced by external best practice only. This means that 28 sets of raters agreed that there was mixed influence on the final product - what one would expect from a hybrid. The average number of sources that raters showed were influencing reform designs was 2.35 , and the dominant influence were 'emerging practices within the country' (this was the dominant influence in 14 cases, and a secondary influence in 5 other cases). This suggests that most positive deviants were hybrid solutions that emerged from internal processes and were heavily influenced by emerging internal ideas.

\section{PDIA and SLDC as one theory or two separate explanations?}

Given the above, it appears that evidence arising from the case survey is more supportive of a problem driven iterative adaptation (PDIA) explanation than a solution and leader driven change (SLDC) explanation: Abnormally successful reforms (or positive deviants) seem to be motivated by problems more than solutions; The positive deviant reforms appear to emerge from a process 
of experimentation and learning more often than through a predesigned, planned out process; These positive outliers seem to result from the engagement of many leaders more commonly than from the leadership of one outstanding individual; The successes produce hybrids more often than pure-form best practices.

Whereas there is evidence to suggest that the above conclusions might be strong takeaways from this study, however, it is clear that the story is not open and closed. There is data suggesting that at least some aspects of SLDC contribute to the explanation of positive deviance. A number of raters did find that solutions existed at the start of some reforms, for instance, and a number of raters also found that reform processes were pre-planned and followed the plan. Furthermore, nearly half of the raters agreed that a single leader was driving the process.

The study shows how such SLDC characteristics might overlap with PDIA characteristics to facilitate a blended approach of producing positive deviant reforms. This is most evident when looking at the way raters assessed questions asking about the interaction of problems and (potential) solutions in motivating reforms. Indicating that problems alone do not motivate reform, 18 pairs of raters agreed that, 'There was a problem people wanted to address, and there was a proposal for action.' In contrast, only 7 pairs of raters agreed that, 'There was a problem people wanted to address, even though no one really knew what to do. ${ }^{26}$ This suggests that even where there was a problem motivating reform, some proposal had to be on the table to guide action. This argument echoes theories of institutional change that emphasize the importance of some disruption to a system and the presence of some viable alternative to the status quo (Andrews 2013a). Such argument is supported by the fact that raters of 13 cases agreed with the comment that, 'reform content was partially known at the start. ${ }^{27}$ Combined with the 6 cases where reform content was fully known at the start, this data shows that over half of the cases began with some level of knowledge about solutions. Such knowledge might have been an important motivation for reform, even where problems also motivated intervention.

\footnotetext{
${ }^{26}$ There was high rater agreement for this question (93\%).

${ }^{27}$ In respect of this question, 13 out of 30 sets of raters scored above 4, 6 scored below 2, and the average was 3.08 out of 5 . The inter-rater agreement was $70 \%$. Interestingly, in the cases where coders noted that the reform content was fully known, low scores were given for the question 'was reform content only partially known': 4 answered ' 2 ' and three answered ' 1.5 '.
} 
One could see the potential blend of SLDC and PDIA arguments working in other ways as well. It is apparent, for instance, that some interventions in this ISS sample began with at least partial knowledge of a solution and simultaneously involved experimental implementation processes. These cases all seem to have generated new hybrids (as authors like Ostrom (2008) would predict). Such is the example of many cases across the literature, where flexible design processes allow an initial idea to morph into something new that can be fitted to complex contexts (Andrews and Moynihan 2002; Andrews and Shah 2002).

However, the blended theory one might imagine when considering this argument falls short of a full-blown, shared theory. In a sense it is more like a PDIA-lite version, where change is motivated by both problems and a potential solution but the flexible process of implementation still means that the proposed solution gets shaped to fit the context. One is no longer talking about a blended theory if this interpretation is accepted, but then it still becomes important to think about how SLDC and PDIA relate. Interestingly, when one examines bivariate correlations, it is actually apparent that the SLDC and PDIA hypotheses stand as separate explanations - as one would expect in two different theories.

Correlations between the variables were calculated using Kendall's tau-b (with Fisher's exact test used to test the significance of the relationships), ${ }^{28}$ and a number of important observations arose. First, there was a positive correlation of 0.65 (significant at the 10 percent level) between the variable capturing whether reforms were fully known and the variable reflecting whether reforms were preplanned (as per hypotheses 1 and 2, in SLDC). This does not seem like a high correlation or level of significance, but prior studies suggest that in this kind of analysis any correlation above 0.45 should be considered high and any significance of 90 or higher should be considered 'significant'. ${ }^{29}$ Given this, the high, positive and significant correlation observed suggests the existence of a set of cases where these two SLDC hypotheses interacted to explain success. The cases in this sample were the Kenya Open Data Initiative, Agile Policymaking in Rwanda, Liberia’s Philanthropy Secretariat, Nigeria’s Federal Inland

\footnotetext{
${ }^{28}$ Kendall's tau-b correlation coefficient is based on the number of concordant and discordant pairs of observations in the table, using a correction for ties. It is an appropriate nonparametric measure of correlation for ordinal data (Beierle and Konisky 2000; Bullock and Tubbs 1987). Fisher's exact test measures the probability of observing a contingency table that shows at least as much association between variables as that actually observed.

${ }^{29}$ Beierle and Konisky $(2000,596)$. It should be noted that the spearman correlation was 0.81 .
} 
Revenue Service, Sergio Fajardo and Medellin, Public Sector Reform in Georgia, Civil Service Reform in Bangladesh, and Police Reform in Lesotho.

Similarly, the first two PDIA variables (reflecting a problem motivation and emergent, experimental process, as per hypotheses 5 and 6) had a high correlation (0.63) that was significant at the $5 \%$ level. ${ }^{30}$ These statistics show that a set of positive deviants had both a problem motivation and an emergent, experimental implementation process. This sub-set included the following cases (with others): Improving Decision Making at the Center of Government: Liberia's Cabinet Secretariat 2009-12; Matching Goodwill with National Priorities: Liberia's Philanthropy Secretariat, 2008 - 2012; Building Capacity, Changing Norms: Rapid Results in Madagascar, 2005 - 2009; Promoting Accountability, Monitoring Services: Textbook Procurement and Delivery, The Philippines, 2002-2005; Rebuilding the Civil Service After War: Rwanda After the Genocide, 1998-2009; and The Promise of Imihigo: Decentralized Service Delivery in Rwanda, 2006-2010.

The evidence thus suggests that there may be two viable paths towards achieving positive deviance in public sector reform in development. One path (which seems to have fewer cases associated with it) is SLDC, where one needs a driving idea and clear plan for implementation. The other (wider) path is PDIA, where a problem drives change and a flexible process allows experimentation, learning, and adjustment. The two paths do not overlap very much either, if the data is anything to go by. For instance, there was a negative relationship between the variable capturing whether interventions were problem driven (hypothesis 5, in PDIA) and the variables reflecting whether reforms were solution driven and preplanned (hypotheses 1 and 2, in SLDC). ${ }^{31}$ The correlation between the variable showing degree of emergence and experimentation (another key PDIA variable, as per hypothesis 6) and the SLDC variable for preplanned implementation (hypothesis 2) was also negative (-0.59) and significant at the 10\% level. ${ }^{32}$ This suggests that there is a big difference between SLDC reforms that are motivated by a solution and follow a predetermined path and PDIA reforms that begin with a strong focus on solving problems (and only a partial focus on some or other potential solution) and are allowed to emerge through experimentation.

\footnotetext{
${ }^{30}$ The spearman correlation was higher, at 0.82 .

${ }^{31}$ The spearman correlations were -0.43 and -0.40 .

${ }^{32}$ The spearman correlations were -0.33 and -0.38 .
} 


\section{Conclusion}

It serves as useful to remind readers that the case survey evidence used in this study was drawn from an analysis of thirty narratives of public sector institutional reform published by the Innovations in Successful Society (ISS) program at Princeton University. The ISS cases are examples of reforms that have yielded functional improvement in some of the toughest contexts in development, where reform failure is far more normal. As such, they are considered abnormal successes - or positive deviants - and are the kinds of reform experiences where one would hope to learn a great deal. The current paper intends to contribute to a better understanding of this kind of positive deviance in public sector reform in developing countries. It focuses on learning about the processes through which such deviants arise and are implemented. Rather than testing a particular theory, it has set two theories in competition with each other and asked whether evidence from the case survey study supports one or the other (or parts of both).

As presented, case survey evidence seems more supportive of problem driven iterative adaptation (PDIA) as a theory explaining positive deviance. In support of major PDIA hypotheses, the majority of reforms in the sample seem to have been motivated by a problem, implemented through flexible processes involving experimentation, and led by groups. Also supporting PDIA is the fact that over 90 percent of these reforms ultimately produced hybrid products that did not resemble pure-form best practices. This strong evidence is particularly impressive given potential bias in the ISS sample towards an SLDC narrative (as discussed). However, there is also evidence that solution and leader driven change (SLDC) has some value in the discussion about positive deviance. There were some reforms that seem to have been motivated by clearly defined solutions, implemented according to plan, led by a single leader, and ultimately proved successful in introducing a functional 'best practice' product.

This evidence suggests that SLDC and PDIA offer two different paths for producing positive deviance in public sector reform in developing countries. The PDIA path appears much wider than the SLDC path, seemingly explaining more of the cases than SLDC. Future work should explore why this is so. It may be that PDIA is the approach required when reforms are in particularly complex areas, contextual impediments are severe and difficult to navigate, and there 
are no clear solutions. SLDC could work when reforms are more technical and do not demand contextual fit (a type of reform that fits into a much smaller sub-set of interventions).

It is also interesting that some cases of positive deviance seem to be explained through a softened version of PDIA (PDIA-lite); where positive deviants are motivated by both problems and a proposed (partially identified) solution but where flexible implementation processes still ensure solutions are shaped to the context. Future research needs to examine whether this kind of PDIA-lite intervention is more common than an extreme version. This would be a very useful finding for those in the development community who might be eager to experiment with PDIA approaches but need to do so within the parameters of a traditional project preparation process (that incentivizes a more direct SLDC orientation). If PDIA can start with both a problem and solution motivation it might be possible to fit such approach into a results based lending instrument — as long as there is flexibility and learning in implementation.

The evidence from this study needs to be qualified, however, and applied to practice with care. The study is limited because of a lack of counterfactual cases, for instance. It is unclear whether elements of PDIA or SLDC would be more or less present in less successful reform cases. Future research could build on the work in this paper by expanding the sample to include both positive deviants and more-normal reform failures. Adopting a larger and more varied case sample in future research could also help in managing potential bias one must expect when drawing cases from one source (as in this study). Bias could be further mitigated in future work by drawing on some of the lessons about coding emerging in this study. In particular, the variables used to capture leadership proved difficult to craft_partly because raters disagreed on basic questions (like whether there was a single leader). It is important to specify exactly what one is looking for in this kind of study and it would be better to ask more explicitly about who provided what functional contributions to the reform (as was asked in a secondary set of questions in the current study).

Future studies are definitely needed before one can explain positive deviance in public sector reform in developing countries. These studies could expand on the theoretical frameworks considered for assessment (not just the sample variation). There is significant scope to buildmore on work like Leonard (2010) and on past work like Bond and Hulme (1999) in the 'process projects' approach of the 1980s, and of course people like Hirschman (1967). Even without these 
additional views, however, the current paper has contributed to a better understanding of such deviance. It yields the lesson that two paths exist to produce abnormally successful reform, but one is much wider than the other and will probably generate more success in more cases. This latter path is one in which reforms take shape through a process called problem driven iterative adaptation (PDIA) where they are motivated by problems, emerge through experimentation and learning, are led by groups, and ultimately produce new hybrid solutions that make governments work better than they did before reforms began. In reflecting on such path, one is reminded of Albert O. Hirschman's writing on implementation in development (Hirschman 1967, 35) and the importance of thinking about development projects as journeys:

"The term "implementation" understates the complexity of the task of carrying out projects that are affected by a high degree of initial ignorance and uncertainty. Here "project implementation" may often mean in fact a long voyage of discovery in the most varied domains, from technology to politics." 


\section{Annex 1. The thirty ISS cases used in this study}

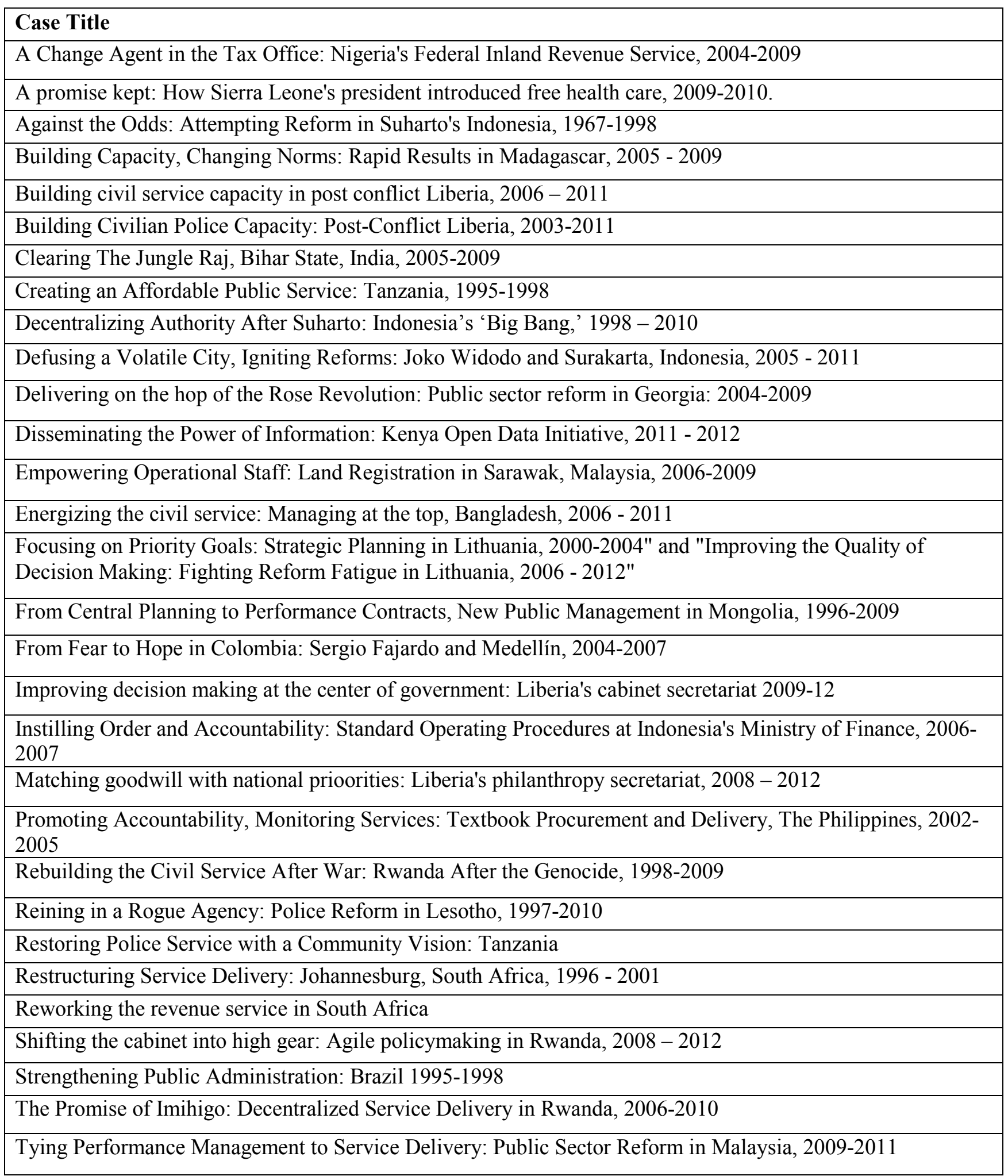




\section{References}

African Development Bank. (2012). Governance Strategic Directions and Action Plan 20082012. Tunis: African Development Bank.

Andrews, M. (2005). Voice Mechanisms and Local Government Fiscal Outcomes: How Does Civic Pressure and Participation Influence Accountability? In Shah, A. (Ed). Public Expenditure Analysis. Washington, D.C.: World Bank, 217-241.

Andrews, M. (2008). Effective political engagement. In Odugbemi, S. \& Jacobson,T., (Eds.) Governance Reform Under Real World Conditions. Washington, D.C.: World Bank, 95111.

Andrews, M. (2010).How Far Have Public Financial Management Reforms Come in Africa? HKS Working Paper Series RWP10-018, May 2010.

Andrews, M. (2011). Which organizational attributes are amenable to external reform? An empirical study of African public financial management. International Public Management Journal, Vol. 5 (2), 135-154.

Andrews, M. (2013a). The Limits of Institutional Reform in Development. New York, N.Y.: Cambridge University Press.

Andrews, M. (2013b). How do Governments Get Great? HKS Working Paper Series RWP13020, April 2013.

Andrews, M., McConnell, J., \& Wescott, A. (2010). Development as Leadership Led Change. Washington, D.C.: World Bank.

Andrews, M. \& Moynihan, D. (2002). Why reforms do not always have to "work" to succeed. Public Performance \& Management Review, Vol.25, 282-297. Andrews, M. \& Moynihan, D. 2002. Why reforms do not always have to "work" to succeed. Public Performance \& Management Review, Vol.25, 282-297.

Andrews, M., Pritchett, L., \& Woolcock, M. 2013. Escaping Capability Traps Through Problem Driven Iterative Adaptation (PDIA). World Development Vol. 51, 234-244.

Asian Development Bank. (2009). ADB Support for Public Sector Reforms in the Pacific: Enhance Results through Ownership, Capacity, and Continuity. Manila: ADB. Asian Development Bank. (2011). 2011 Development Effectiveness Review. Manila: ADB. 
Barzelay, M. (2007). Learning from Second-Hand Experience: Methodology for Extrapolationoriented Case Research, Governance, 20 (3), 521-543.

Bebbington, A., \& McCourt, W. (eds) (2007). Development Success: Statecraft in the South. Basingstoke: Palgrave Macmillan.

Beierle, T.C., \& Cayford, J. (2002). Democracy in Practice: Public Participation in Environmental Decisions. Washington, D.C.: Resources for the Future.

Beierle, T.C. \& Konisky, D.M. (2000). Values, Conflict, and Trust in Participatory Environmental Planning. Journal of Policy Analysis and Management, Vol. 19 (4), $587-$ 602.

Bond, R., \& Hulme, D. (1999). Process Approaches to Development: Theory and Sri Lankan Practice. World Development, Vol. 27 (8), 1339-1358.

Boubakri, N., Cosset, J.C., \& Guedhami, O. (2009). From state to private ownership: Issues from strategic industries. Journal of Banking and Finance, 33 (2), 367-379.

Brady, D. \& M. Spence (2010) Leadership and Politics: A Perspective from the Commission on Growth and Development. In D. Brady and M.Spence (Eds.) Leadership and Growth. Washington, D.C.: World Bank, 1-17.

Bullock, R. \& Tubbs, M. (1987). The case meta-analysis method for OD. Research in Organizational Change and Development, Vol.1, 171-228.

Busenitz, L. W., Gomez, C., \& Spencer, J. W. 2000. Country institutional profiles: Unlocking entrepreneurial phenomena. Academy of Management Journal, 43(5), 994-1003.

Cameron, K.S. (1986). Effectiveness as paradox: Consensus and conflict in conceptions of organizational effectiveness. Management Science, 32, 539-553.

Chambers, R. (1997). Whose Reality Counts? Putting the First Last. London: IT Publications

Dacin, M.T., Goodstein, J., \& Scott, W.R. (2002). Institutional theory and institutional change: Introduction to the special research forum. Academy of Management Journal, 45(1), 4557.

Department for International Development. (2011). Governance Portfolio Review Summary. London: DFID. 
de Renzio, P., Andrews, M., \& Mills, Z. (2010). Evaluation of Donor Support to Public Financial Management (PFM) Reform in Developing Countries. Overseas Development Institute: London.

Dorado, S. (2005). Institutional Entrepreneurship, Partaking, and Covening. Organization Studies, 26(3), 385-414.

Garud, R. \& Karnøe, P. (2003). Bricolage versus breakthrough: distributed and embedded agency in technology entrepreneurship. Research Policy, 32, 277-300.

Greenwood, R., \& Suddaby, R. (2006). Institutional entrepreneurship in mature fields: The Big Five accounting firms. Academy of Management Journal, 49, 27-48.

Greenwood, R., Suddaby, R., \& Hinings, C. R. (2002). Theorising change: the role of professional associations in the transformation of institutional Fields. Academy of Management Journal, 45(1), 58-80.

Grindle, M. (1997). Divergent Cultures? When Public Organizations Perform Well in Developing Countries. World Development, Vol. 25 (4), 481-95.

Grindle, M. (2004). Despite the Odds: The Contentious Politics of Education Reform. Princeton: Princeton University Press.

Grindle, M., \& Thomas, J. (1991). Public Choice and Policy Change: The Political Economy of Reform in Developing Countries. Baltimore: The Johns Hopkins University Press.

Hackman, J.R. \& Walton, R.E. (1986). Leading Groups in Organizations. In Goodman, P.S. (ed.). Designing Effective Work Groups. San Francisco: Jossey-Bass, 72-119.

Heredia, B., \& Schneider, B.R. (2002). The political economy of administrative reform in developing countries. In B.R. Schneider and B. Heredia (eds.) Reinventing Leviathan: The Politics of Administrative Reform in Developing Countries. Miami: North-South Center Press, 1-29.

Herek, G.M., Janis, I.L., \& Huth, P. (1987). Decision making during international crises-Is quality of process related to outcome? Journal of Conflict Resolution, 31 (2), 94-112.

Hirschman, A. (1967). Development Projects Observed. Washington, D.C.: Brookings.

Karikari, J.A. (2010). Governance, Financial Liberalization, and Financial Development in SubSaharan Africa. African Economic Conference, November 2010. Available at: http://papers.ssrn.com/sol3/papers.cfm?abstract_id=1733322 
Korten, D.C. (1980). Community organization and rural development: A learning process approach. Public Administration Review (September/October).

Larsson, R. (1993). Case Survey Methodology: Quantitative Analysis of Patterns Across Case Studies. The Academy of Management Journal. 36 (6), 1515-1546.

Larsson, R., \& Lubatkin, M. (2001). Achieving Acculturation in Mergers and Acquisitions: An International Case Survey. Human Relations, Vol.54 (12): 1573-1607.

Leonard, D. (1991). African Successes: Four Public Managers of Kenyan Rural Development. Berkeley: University of California Press.

Leonard, D. (2010). 'Pockets' of effective agencies in weak governance states: Where are they likely and why does it matter? Public Administration and Development, Vol.30 (2), 91101.

Lindblom, C., (1959). The Science of 'Muddling Through'. Public Administration Review, 19, 79-88.

Lucas, W.A. (1974). The case survey method: Aggregating case experience. Santa Monica. McCay, B.J. (2002). Emergence of Institutions for the Commons: Contexts, Situations, and Events. In E. Ostrom (Ed.). The drama of the commons. Washington, D.C.: National Research Council, 361-399.

Mintzberg, H., Raisinghani, D., \& Theoret, A. (1976). The structure of "unstructured" decision processes, Administrative Science Quarterly, 21 (2), 246-275.

Moloney, K. (2009). Public administration and governance: a sector-level analysis of World Bank aid. International Review of Administrative Sciences. 75(4), 609-627.

Newig, J., \& Fritsch, O. (2009) The case survey method and applications in political science. Paper presented at 2009 APSA meeting.

Obtsfeld, M. (2009). International Finance and Growth in Developing Countries: What Have We Learned? IMF Staff Papers 56, 63-111

Ostrom, E. (2008). Design Principles of Robust Property-Rights Institutions: What have We Learned? In K.G. Ingram, and Y-H. Hong (Eds.). Property Rights and Land Policies. Cambridge, MA.: Lincoln Institute of Land Policy, 25-51.

Owusu, F. (2006). On Public Organizations in Ghana: What Differentiates Good Performers from Poor Performers? African Development Review Vol. 18, 471-485. 
Pascale, R., Sternin, J., \& Sternin, M. (2010). The Power of Positive Deviance: How Unlikely Innovators Solve the World's Toughest Problems. Cambridge: Harvard Business Review Press.

Pritchett, L., Woolcock, M., \& Andrews, M. 2013. Looking Like a State: Techniques of Persistent Failure in State Capability for Implementation. The Journal of Development Studies Vol. 49 (1), 1-18.

Roberts, J. \& Andrews, M. (2005). Something Funny Happened on the Way to Reform Success... The Case of Budget Reform Implementation in Ghana. International Journal of Public Administration, 28 (3-4), 291-311.

Rodrik, D. (2003). In Search of Prosperity: Analytic Narratives on Economic Growth. Princeton: Princeton University Press.

Rondinelli, D.A. (1993). Development Projects as Policy Experiments: An Adaptive Approach to Development Administration. $2^{\text {nd }}$ Edition. London: Methuen.

Rose, R. (2003). What's Wrong with Best Practice Policies--And Why Relevant Practices Are Better. On Target? Government by Measurement. London: House of Commons Public Administration Select Committee HC 62-II, 2003, 307-317.

Schneider, B.R. (1991). Politics Within the State: Elite Bureaucrats and Industrial Policy in Authoritarian Brazil. Pittsburgh: University of Pittsburgh Press.

Seo, M.G., \& Creed, W.E.D. (2002). Institutional Contradictions, Praxis and Institutional Change: A Dialectical Perspective. Academy of Management Review, 27(2), 222-247.

Tendler, J. (1997). Good Government in the Tropics. Baltimore: Johns Hopkins University Press. Uphoff, N. (1985). Fitting Projects to People. In Putting People First: Sociological Variables in Rural Development. Cernea, M. (Ed.) New York: Oxford University Press.

Uphoff, N., Esman, M.J., \& Krishna, A. (1998). Reasons for success: learning from instructive experiences in rural development. West Hartford, Conn.: Kumarian Press.

VanLandingham,G., Wellman,M. \& Andrews, M. (2005). Useful, But Not a PanaceaPerformance-Based Program Budgeting in Florida. International Journal of Public Administration, , 28 (3-4), 233-253.

Vis, B. and van Kersbergen, K. (2007). Why and how do Political Actors Pursue Risky Reforms? Journal of Theoretical Politics Vol. 19. No.2: 153-172. 
Wolf, P. (1993). A case survey of bureaucratic effectiveness in US cabinet agencies: Preliminary results. Journal of Public Administration, Research and Theory, Vol.3 (2): 161-181.

World Bank. (2008). Public Sector Reform: What Works and Why? Washington, D.C.: World Bank.

World Bank. (2009). Improving Effectiveness and Outcomes for the Poor in Health, Nutrition, and Population: An Evaluation of World Bank Group Support Since 1997. Washington, D.C.: World Bank.

World Bank. (2011). IEG Annual Report 2011. Washington, D.C.: World Bank.

World Bank. (2012). World Bank Approach to Public Sector Management 2011-2020: Better Results from Public Sector Institutions (Draft). Washington, D.C.: World Bank.

Yin, R., \& Heald, K. (1975). Using the Case Method to Analyze Policy Studies. Administrative Science Quarterly, Vol.20 (3): 371-381. 